\title{
DESKRIPSI DAN DAYA HASIL 19 KLON UBI KAYU (Manihot esculenta Crantz) DI KEBUN PERCOBAAN UNILA, NATAR, LAMPUNG SELATAN
}

\section{DESCRIPTION AND YIELD POTENTIAL OF 19 CASSAVA CLONES (Manihot esculenta Crantz) IN UNIVERSITY OF LAMPUNG RESEARCH CENTRE IN NATAR SOUTH LAMPUNG}

\author{
Eka Setiawati*, Setyo Dwi Utomo, Niar Nurmauli, Sunyoto \\ Jurusan Agroteknologi, Fakultas Pertanian, Universitas Lampung \\ Jl Sumantri Brojonegoro 1, Bandar Lampung 35145, Indonesia \\ *Email:ekasetiawatifp@gmail.com
}

\begin{abstract}
The aim of this research was to obtain a description of cassava clones comparing them with the national superior clones, namely UJ 5. The research was conducted on cassava plants aged 9 months after planting or during the harvest period which was located in the research field in Muara Putih Village Natar, South Lampung. Based on observations of 19 cassava clones, there were several clones with high yielding power. The clones with the highest yield were Daniel 40th branch with $49.59 \mathrm{t} / \mathrm{ha}, \mathrm{BL} 8-1$ with $48.83 \mathrm{t} /$ ha, SL 36 with $44.25 t$ / ha, Mulyo 190516 with $39.93 t$ / ha, MU 35 with $31.90 t /$ ha, and UJ 5 as a comparison in the order of 18 with a result of $11.37 \mathrm{t} / \mathrm{ha}$. There are 17 cassava clones which have higher yield potential than the comparison clones of UJ 5 as a national superior clone.
\end{abstract}

Keywords: Cassava, clones, description, yield

\begin{abstract}
ABSTRAK
Penelitian bertujuan untuk mendapatkan deskripsi klon ubi kayu membandingkannya dengan klon unggul nasional yaitu UJ 5. Penelitian dilakukan pada tanaman ubi kayu umur 9 bulan setelah tanam atau saat masa panen yang bertempat di kebun percobaan Desa Muara Putih, Natar, Lampung Selatan. Berdasarkan pengamatan terhadap 19 klon ubi kayu, didapatkan beberapa klon dengan daya hasil tinggi. Klon dengan daya hasil tertinggi yaitu Daniel Cabang 40 dengan 49,59 t/ha, BL 8-1 dengan 48,83 t/ha, SL 36 dengan 44,25 t/ha, Mulyo 190516 dengan 39,93 t/ha, MU 35 dengan 31,90 t/ha, serta UJ 5 sebagai pembanding pada urutan 18 dengan hasil 11,37 t/ha. Terdapat 17 klon ubi kayu yang memiliki potensi panen lebih tinggi dari klon pembanding UJ 5 sebagai klon unggul nasional.
\end{abstract}

Kata kunci: Deskripsi, daya hasil, klon, ubi kayu. 


\section{PENDAHULUAN}

Data BPS (Badan Pusat Statistik) tahun 2015 menujukan penurunan produksi ubi kayu pada tahun 2013 hingga 2015. Salah satu upaya untuk menanggulangi penurunan produksi tersebut adalah dengan pemuliaan tanaman. Pemuliaan tanaman merupakan tindakan seleksi berbagai sumber tanaman dalam sebuah populasi yang memiliki karakter unggul untuk dikembangbiakkan sebagai benih dan bibitunggul (Dewi, 2016).

Pemuliaan tanaman dilakukan dengan menyatukan sifat-sifat unggul dari berbagai klon menjadi varietas unggul baru. Klon yang digunakan sebagai induk dalam pemuliaan harus memiliki data deskripsi yang lengkap.

Fungsi utama deskripsi klon adalah untuk memudahkan pemulia dalam mengenali masing-masing klon dengan ciri fisiknya. Hasil seleksi dari beberapa klon pada pemuliaan tanaman ubi kayu akan dihasilkan klon unggul. Calon klon tersebut harus memenuhi beberapa persyaratan, salah satunya adalah tersedianya deskripsi yang lengkap dan jelas, deskripsi ini berguna untuk identifikasi dan pengenalan klon secara akurat sebelum dilakukan pelepasan menjadi klon unggul baru. Saat ini terdapat sebuah klon unggul yaitu UJ5. Klon UJ 5 merupakan klon unggul nasional dengan keunggulan produksi tinggi, yakni mencapai 40-48 t/ ha (Nugraha, 2015).Klon UJ5 dapat dijadikan rujukan pembanding untuk klon yang akan diteliti. Belum adanya deskripsi yang lengkap terhadap 19klon baru maka perlu adanya penelitian terkait deskripsi 19 klon ubi kayu serta mengetahui daya hasil 19 klon ubi kayu yang diuji dengan membandingkan dengan klon UJ5.

\section{BAHAN DAN METODE}

Penelitian dilakukan di Kebun Percobaan Universitas Lampung yang terletak di Desa Muara Putih, Kecamatan Natar, Lampung Selatan, Lampung pada bulan Maret hingga April 2017, pada 19 klon yang berusia 33 - 36 minggu setelah tanam (MST).

Tabel 1. Identitas klon-klon ubi kayu.

\begin{tabular}{clll}
\hline No klon & \multicolumn{1}{c}{ Nama Klon } & \multicolumn{1}{c}{ Deskripsi } & \multicolumn{1}{c}{ Asal Daerah } \\
\hline 1 & Thailand Tinggi & Klon lokal & Lampung Selatan \\
2 & MU 111 & F1 keturunan Mentik Urang & Lampung Tengah \\
3 & MU 35 & F1 keturunan Mentik Urang & Lampung Tengah \\
4 & MU 55 & F1 keturunan Mentik Urang & Lampung Tengah \\
5 & SL 30 & F1 keturunan Sayur Liwa & Liwa, Lampung Barat \\
6 & SL 36 & F1 keturunan Sayur Liwa & Liwa, Lampung Barat \\
7 & SL 201 & F1 keturunan Sayur Liwa & Liwa, Lampung Barat \\
8 & SL 121 & F1 keturunan Sayur Liwa & Liwa, Lampung Barat \\
9 & SL 106 & F1 keturunan Sayur Liwa & Liwa, Lampung Barat \\
10 & Mulyo 190516 & F1 keturunan tetua Mulyo & Liwa, Lampung Barat \\
11 & UJ5 & Varietas unggul nasional & Liwa, Lampung Barat \\
12 & UJ3 & Varietas unggul nasional & Liwa, Lampung Barat \\
13 & UJ 3 Kecil Pekalongan & Klon lokal & Pekalongan, Lampung \\
14 & CMM 96-1-102 & F1 keturunan klon CMM 96-1 & Balitkabi \\
15 & CMM 97-6-1 & F1 keturunan CMM 97-6-1 & Balitkabi \\
16 & Daniel Cabang 40 & Klon lokal & Sragen, Jawa Tengah \\
17 & BL 8-1 & Klon lokal & Bandar Lampung \\
18 & Litbang UK 2 & Varietas unggul nasional & Bandar Lampung \\
19 & Korem Gatam & Klon lokal dari Korem Garuda Hitam & Bandar Lampung \\
\hline
\end{tabular}


Bahan yang digunakan dalampenelitian ini adalah 19 klon ubi kayu (Tabel 1). Sampel diambil secara acak pada petak percobaan yang tercantum pada Gambar 1. Pengamatan dilakukan secara kuantitatif dan kualitatif yang terbagi pada variabel vegetatif dan generatif.

Variabel vegetatif yang diamati diantaranya warna pucuk daun, warna daun, warna permukaan atas tangkai daun, warna permukaan bawah tangkai daun, warna kulit luar batang, warna korteks batang, tinggi tanaman $(\mathrm{cm})$, diameter batang tanaman $(\mathrm{mm})$, tingkat percabangan tertinggi, panjang tangkai daun $(\mathrm{cm})$, panjang lobus daun $(\mathrm{cm})$, lebar lobus daun $(\mathrm{cm})$, lebar daun $(\mathrm{cm})$, jumlah lobus daun, bobot berangkasan, persentase tanaman bercabang.

Variabel generatif yang diamati meliputi bentuk umbi, warna kulit ubi bagian luar, tekstur kulit ubi, warna kulit ubi bagian dalam, dan warna daging ubi, diameter penyebaran ubi $(\mathrm{cm})$, jumlah ubi per tanaman, bobot ubi per tanaman, persen pembungaan dan kadar pati.
Pengamatan kualitatifberupa warna dilakukan dengan membandingkan keadaan di lapang dengan buku panduan Selected Morphological and Agronomic Descriptors for The Characterization of Cassava yang disusun oleh Fukuda dkk yang diterbitkan sebagai jurnal oleh International Institute of Tropical Agriculture(IITA), Nigeria.

\section{HASIL DAN PEMBAHASAN}

Dalam melakukan perakitan varietas unggul ubi kayu terdapat beberapa tahapan yaitu: 1) penciptaan dan perluasan keragaman genetik populasi awal, 2) evaluasi karakter agronomi dan seleksi kecambah dan tanaman yang tumbuh dari biji botani, 3) evaluasi dan seleksi klon, 4) uji daya hasil pendahuluan, dan 5) uji daya hasil lanjutan (Ceballos dkk, 2002). Varietas lama yang telah mengalami penurunan menjadi permasalahan bahan tanam di kalangan petani (Kawano, 2003) sehingga perlu dilakukan pemuliaan.

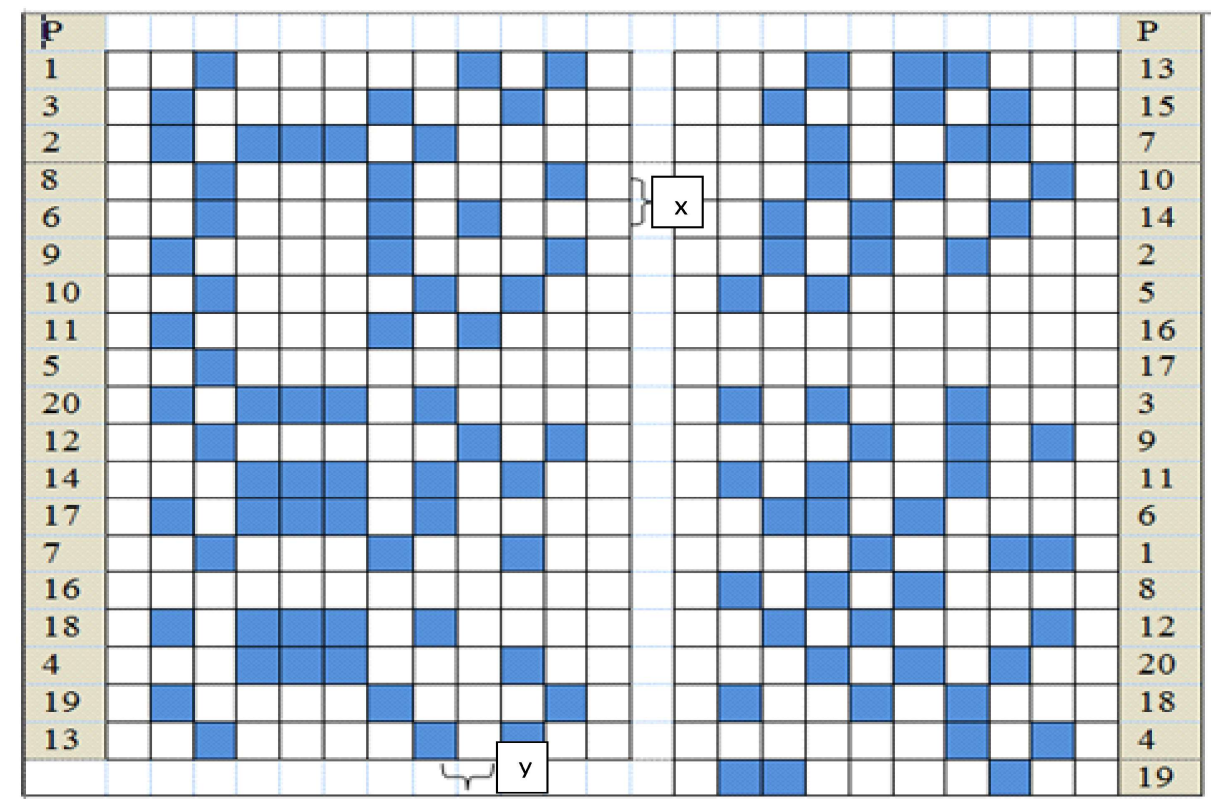

Gambar 1. Tata Letak Pengambilan Sampel 
Program pemuliaan tanaman ubi kayu di Indonesia, bertujuan untuk merakit varietas/klon unggul dengan menghasilkan umbi yang manis ataupun pahit yang berproduksi tinggi, toleran terhadap serangan OPT utama, percabangan tidak intensif, toleran terhadap kondisi tanah marjinal dan iklim yang tidak menentu, mempunyai bentuk umbi bagus, dan berumur genjah (Sundari dkk, 2010). Menurut Utomo, (2012) pemuliaan tanaman dapat dilakukan dengan 3 cara, yaitu: 1) Melakukan pemilihan tanaman pada populasi yang sudah ada, 2) Melakukan kombinasi sifat-sifat genetik yang diinginkan (secara generatif maupun vegetatif), dan 3) Melalui rekayasa genetika.

Karakter kualitatif yang diamati menunjukkan keragaman pada setiap variabel yang diamati. Keragaman variabel kualitatif menunjukkan luasnya plasma nutfah yang dapat dikembangkan dalam proses pemuliaan tanaman. Keragaman karakter kualitatif diharapkan akan lebih meningkatkan ketahanan satu klon baru dari cekaman biotik dan biotik (Borlaug, 1981). Data variabel kualitatif akan memudahkan peneliti serta pelaku pertanian untuk mengenal dan memilih sifat-sifat yang ingin dijadikan bahan dalam pemuliaan.

Klon UJ 5 merupakan klon unggul nasional dengan keunggulan produksi tinggi, yakni mencapai 4048 t/ha (Nugraha,2015). Dwidjoseputro (1990) dalam Adrianus (2012) mengatakan bahwa berat ubi dipengaruhi oleh banyak ubi yang terbentuk, semakin banyak ubi maka semakin berat bobot yang dihasilkan. Banyaknya ubi yang terbentuk mempengaruhi berat ubi yang dihasilkan. Pada penelitian ini produksi umbi klon UJ 5 dapat menghasilkan 568,75 g yang setara dengan 11,375 t/ha. Pada penelitian ini, klon yang mendapatkan bobot umbi tertinggi antara lain Daniel Cabang 40 dengan kemampuan produksi 49,58 t/ha, klon BL 8-1 dengan produksi 48,83 t/ha, klon SL 36 dengan produksi 44,25 t/ha, klon Mulyo 190516 dengan produksi 39,93 t/ha dan MU 35 dengan produksi 31,9 t/ha (Tabel 2).

Pada penelitian ini, UJ 5 menghasilkan rata-rata 7,75 umbi/tanaman. Klon dengan jumlah umbi/tanaman tertinggi pada penelitian ini antara lain SL 36 dengan 8,17 umbi/tanaman, MU 35 dengan 8 umbi/tanaman,

Tabel 2. Nilai tertinggi variabel umbi/tanaman, jumlah umbi/tanaman, rendemen pati dan indeks panen

\begin{tabular}{clccccc}
\hline No & \multicolumn{1}{c}{ Klon } & $\begin{array}{c}\text { BobotUbi } \\
\text { perTanaman }(\mathrm{g})\end{array}$ & $\begin{array}{c}\text { JumlahUbi } \\
\text { per Tanaman }\end{array}$ & $\begin{array}{c}\text { RendemenPati } \\
(\%)\end{array}$ & $\begin{array}{c}\text { IndeksPanen } \\
(\%)\end{array}$ & $\begin{array}{c}\text { Produksi } \\
\text { t/ha }\end{array}$ \\
\hline 1 & Daniel Cabang 40 & $2479,33(1)$ & 6,33 & 31,61 & $41,93(5)$ & $49,59(1)$ \\
2 & BL 8-1 & $2441,67(2)$ & 7,00 & 31,75 & 34,04 & $48,83(2)$ \\
3 & SL 36 & $2212,50(3)$ & $8,17(1)$ & $33,08(4)$ & $42,71(3)$ & $44,25(3)$ \\
4 & Mulyo 190516 & $1996,67(4)$ & 7,17 & 28,28 & 24,81 & $39,93(4)$ \\
5 & MU 35 & $1595,00(5)$ & $8,00(2)$ & 26,98 & 29,28 & $31,9(5)$ \\
6 & UJ5 & 568,75 & $7,75(3)$ & $31,86(5)$ & 22,65 & 11,375 \\
7 & CMM 96-1-102 & 880,83 & $7,67(4)$ & 28,96 & 31,93 & 17,62 \\
8 & MU 111 & 752,50 & $7,33(5)$ & 30,23 & 26,59 & 15,05 \\
9 & CMM 97-6-1 & 836,67 & 4,67 & $35,14(1)$ & 39,28 & 16,73 \\
10 & SL 121 & 1440,83 & 6,50 & $34,28(2)$ & $42,03(4)$ & 28,82 \\
11 & UJ3 & 901,67 & 5,67 & $33,75(3)$ & $66,58(1)$ & 19,2 \\
12 & Thailand Tinggi & 789,83 & 3,83 & 27,85 & $45,18(2)$ & 15,80 \\
\hline
\end{tabular}

Keterangan: Angka yang diikuti tanda kurung adalah urutan klon-klon tertinggi dari masing-masing variabel. 
UJ 5 dengan 7,75 umbi/tanaman, CMM 96-1-102 dengan 7,67 umbi/tanaman, dan MU 111 dengan 7,33 umbi/tanaman (Tabel 3-6).Pada penelitian yang dilakukan Tumewu dik. (2015), ubi kayu dengan aplikasi pemupukan 20 t/ha bokashi kotoran sapi menghasilkan jumlah 10,38 umbi/tanaman. Hal ini menunjukkan bahwa dengan aplikasi pemupukan dapat meningkatkan produksi umbi.

Pada penelitian ini, UJ 5 memiliki kadar pati sebesar $31,86 \%$ bobot basah. Klon dengan kadar pati tertinggi dalam penelitian ini antara lain CMM 97-6-1 dengan kadar pati 35,14\%, SL 121 dengan kadar pati sebesar 34,28\%, UJ 3 dengan kadar pati sebesar 33,75\%, SL 36 dengan kadar pati sebesar $33,08 \%$ dan UJ 5 dengan kadar pati sebesar 31,86\% (Tabel 3-6). Berdasarkan ketetapan menteri pertanian 2000, kadar pati minimal untuk
UJ 5 adalah 19\% (Balitkabi,2015) yang menunjukkan produksi pati pada penelitian ini sudah memenuhi syarat minimal yang ditetapkan.

Indeks panen merupakan salah satu variabel produksi, yaitu bobot umbi berbanding dengan bobot seluruh bagian tanaman. Semakin tinggi nilai indeks panen, maka semakin efisien pula tanaman dalam menghasilkan umbi. Indeks panen UJ 5 dalam penelitian ini adalah 22,65\%. Beberapa klon dengan nilai indeks panen tertinggi dalam penelitian ini adalah UJ 3 dengan indeks panen 66,58\%, Thailand Tinggi dengan nilai indeks panen 45,18\%, SL 36 dengan nilai indeks panen 42,71\%, SL 121 dengan nilai indeks panen 42,04\% dan Daniel Cabang 40 dengan nilai indeks panen 41,93\% (Tabel 3-6).

Berdasarkan penelitian yang telah dilakukan dan dikelompokkan klon-klon dengan nilai tertinggi

Tabel 3. Deskripsi klon Thailand Tinggi, MU III, MU 35, MU 55, dan SL 30

\begin{tabular}{|c|c|c|c|c|c|c|}
\hline No & Variabel & Thailand Tinggi & MU III & MU 35 & MU 55 & SL 30 \\
\hline 1 & warna pucuk daun & hijau tua & hijau keunguan & hijau keunguan & hijau keunguan & hijau keunguan \\
\hline 2 & warna daun & hijau muda & hijau muda & hijau tua & hijau tua & hijau tua \\
\hline 3 & warna permukaan atas daun & hijau kemerahan & merah & merah & merah & Merah \\
\hline 4 & warna permukaan bawah daun & hijau kekuningan & merah & merah kehijauan & hijau & Merah \\
\hline 5 & warna batang & silver & coklat terang & keemasan & abu-abu & keemasan \\
\hline 6 & warna umbi & kuning & putih susu & putih susu & Putih susu & Putih susu \\
\hline 7 & bentuk umbi & tidak beraturan & silinder & silinder & silinder & silinder \\
\hline 8 & warna kulit umbi & kuning & coklat terang & coklat gelap & coklat terang & coklat gelap \\
\hline 9 & warna korteks umbi & kuning & putih & kuning & kuning & Kuning \\
\hline 10 & tekstur kulit umbi & halus & kasar & kasar & kasar & Kasar \\
\hline 11 & tinggi tanaman & 205,17 & 312,45 & 335,92 & 388,25 & 408,23 \\
\hline 12 & diameter batang $(\mathrm{mm})$ & 22,08 & 25,96 & 35,15 & 24,85 & 40,73 \\
\hline 13 & panjang tangkai daun & 15,98 & 15,10 & 16,82 & 12,03 & 15,37 \\
\hline 14 & lebar daun & 18,28 & 18,15 & 25,87 & 21,75 & 20,77 \\
\hline 15 & panjang lobus daun & 12,18 & 11,72 & 15,65 & 14,60 & 13,80 \\
\hline 16 & lebar lobus daun & 3,12 & 5,02 & 3,68 & 3,32 & 1,68 \\
\hline 17 & jumlah lobus & 7 & 7 & 5 & 5 & 7 \\
\hline 18 & jumlah umbi/tanaman & 3,83 & 7,33 & 8,00 & 4,00 & 7,00 \\
\hline 19 & diameter penyebaran umbi & 26,67 & 43,92 & 62,02 & 41,48 & 66,15 \\
\hline 20 & bobot umbi/tanaman & 789,83 & 752,50 & 1595,00 & 1271,50 & 1370,50 \\
\hline 21 & bobot berangkasan & 958,33 & 2077,50 & 3852,50 & 2962,50 & 7228,75 \\
\hline 22 & tingkat percabangan & 1 & 0 & 3 & 2 & 5 \\
\hline 23 & persentase tanaman bercabang & 16,67 & 0 & 70 & 75 & 100 \\
\hline 24 & persen pembunaan & 0 & 0 & 47,5 & 53,57 & 100 \\
\hline 25 & rendemen pati & 27,85 & 30,23 & 26,99 & 27,03 & 27,53 \\
\hline 26 & indeks panen $(\%)$ & 45,18 & 26,59 & 29,28 & 30,03 & 15,94 \\
\hline
\end{tabular}


Tabel 4. Deskripsi klon SL36, SL 201, SL 121, SL 106 dan Mulyo 190516

\begin{tabular}{|c|c|c|c|c|c|c|}
\hline No & Variabel & SL 36 & SL 201 & SL 121 & SL 106 & Mulyo 190516 \\
\hline 1 & warna pucuk daun & hijau muda & hijau muda & $\begin{array}{l}\text { hijau } \\
\text { keunguan }\end{array}$ & hijau muda & hijau keunguan \\
\hline 2 & warna daun & hijau tua & hijau muda & hijau muda & hijau muda & hijau muda \\
\hline 3 & $\begin{array}{l}\text { warna permukaan atas } \\
\text { daun }\end{array}$ & hijau kemerahan & merah & merah & merah kehijauan & $\begin{array}{l}\text { hijau } \\
\text { kemerahan }\end{array}$ \\
\hline 4 & $\begin{array}{l}\text { warna permukaan bawah } \\
\text { daun }\end{array}$ & $\begin{array}{l}\text { hijau } \\
\text { kekuningan }\end{array}$ & merah & merah & hijau kemerahan & hijau kekuningan \\
\hline 5 & warna batang & coklat gelap & abu-abu & silver & coklat terang & abu-abu \\
\hline 6 & warna umbi & putih susu & Putih susu & kuning & kuning & putih \\
\hline 7 & bentuk umbi & silinder & silinder & $\begin{array}{l}\text { tidak } \\
\text { beraturan }\end{array}$ & silinder & silinder \\
\hline 8 & warna kulit umbi & coklat terang & kuning & coklat terang & coklat terang & coklat terang \\
\hline 9 & warna korteks umbi & ungu & putih & kuning & kuning & kuning \\
\hline 10 & tekstur kulit umbi & kasar & halus & kasar & kasar & kasar \\
\hline 11 & tinggi tanaman & 341,10 & 307,42 & 284,98 & 300,65 & 387,37 \\
\hline 12 & diameter batang $(\mathrm{mm})$ & 29,48 & 29,29 & 27,35 & 21,29 & 38,57 \\
\hline 13 & panjang tangkai daun & 15,08 & 12,33 & 11,18 & 12,33 & 11,77 \\
\hline 14 & lebar daun & 20,75 & 23,50 & 16,58 & 21,87 & 17,53 \\
\hline 15 & panjang lobus daun & 15,20 & 14,80 & 9,82 & 14,77 & 11,55 \\
\hline 16 & lebar lobus daun & 2,12 & 1,50 & 2,42 & 1,35 & 3,58 \\
\hline 17 & jumlah lobus & 5 & 5 & 7 & 7 & 5 \\
\hline 18 & jumlah umbi/tanaman & 8,17 & 5,67 & 6,50 & 4,67 & 7,17 \\
\hline 19 & diameter penyebaran umbi & 55,85 & 53,99 & 60,30 & 41,33 & 90,27 \\
\hline 20 & bobot umbi/tanaman & 2212,50 & 688,00 & 1440,83 & 225,83 & 1996,67 \\
\hline 21 & bobot berangkasan & 2967,50 & 3110,83 & 1986,67 & 1679,17 & 6050,00 \\
\hline 22 & tingkat percabangan & 5 & 5 & 4 & 4 & 6 \\
\hline 23 & $\begin{array}{l}\text { persentase tanaman } \\
\text { bercabang }\end{array}$ & 50 & 75 & 100 & 75 & 100 \\
\hline 24 & persen pembunaan & 33,33 & 37,5 & 75 & 50 & 87,5 \\
\hline 25 & rendemen pati & 33,09 & 22,82 & 34,28 & 26,35 & 28,28 \\
\hline 26 & indeks panen $(\%)$ & 42,71 & 18,11 & 42,04 & 11,85 & 24,81 \\
\hline
\end{tabular}

Tabel 5. Deskripsi klon UJ 5, UJ 3, UJ3 Kecil Pekalongan, CMM 96-1-102 dan CMM 97-6-1

\begin{tabular}{|c|c|c|c|c|c|c|}
\hline No & Variabel & UJ5 & UJ3 & UJ 3 Kecil Pekalongan & CMM 96-1- 102 & CMM 97-6-1 \\
\hline 1 & warna pucuk daun & ungu & hijau tua & hijau keunguan & hijau keunguan & hijau tua \\
\hline 2 & warna daun & hijau muda & hijau muda & hijau muda & hijau tua & hijau tua \\
\hline 3 & warna permukaan atas daun & hijau kekuningan & hijau kemerahan & hijau kemerahan & hijau & merah \\
\hline 4 & warna permukaan bawah daun & hijau kekuningan & hijau kekuningan & hijau kekuningan & merah kehijauan & hijau kemerahan \\
\hline 5 & warna batang & abu-abu & silver & silver & abu-abu & coklat terang \\
\hline 6 & warna umbi & Putih susu & Putih susu & kuning & putih susu & putih susu \\
\hline 7 & bentuk umbi & silinder kerucut & silinder & silinder & silinder kerucut & silinder kerucut \\
\hline 8 & warna kulit umbi & putih & kuning & putih & putih & coklat terang \\
\hline 9 & warna korteks umbi & putih & kuning & putih & putih & kuning \\
\hline 10 & tekstur kulit umbi & halus & halus & halus & sedang & kasar \\
\hline 11 & tinggi tanaman & 342,05 & 219,90 & 140,70 & 338,93 & 262,93 \\
\hline 12 & diameter batang $(\mathrm{mm})$ & 25,18 & 16,48 & 13,44 & 22,04 & 21,16 \\
\hline 13 & panjang tangkai daun & 15,53 & 17,47 & 16,77 & 15,00 & 15,43 \\
\hline 14 & lebar daun & 17,80 & 21,07 & 23,17 & 18,38 & 18,20 \\
\hline 15 & panjang lobus daun & 11,08 & 14,25 & 15,30 & 11,98 & 13,50 \\
\hline 16 & lebar lobus daun & 2,77 & 3,68 & 4,08 & 2,67 & 6,63 \\
\hline 17 & jumlah lobus & 7 & 7 & 5 & 7 & 7 \\
\hline 18 & jumlah umbi/tanaman & 7,75 & 7,17 & 5,67 & 7,67 & 4,67 \\
\hline 19 & diameter penyebaran umbi & 42,49 & 39,20 & 38,57 & 37,15 & 45,07 \\
\hline 20 & bobot umbi/tanaman & 568,75 & 960,00 & 901,67 & 880,83 & 836,67 \\
\hline 21 & bobot berangkasan & 1942,50 & 1381,67 & 452,50 & 1877,50 & 1293,33 \\
\hline 22 & tingkat percabangan & 0 & 0 & 0 & 0 & 2 \\
\hline 23 & persentase tanaman bercabang & 50 & 0 & 0 & 0 & 33,33 \\
\hline 24 & persen pembunaan & 38,89 & 0 & 0 & 0 & 33,33 \\
\hline 25 & rendemen pati & 31,86 & 30,80 & 33,75 & 28,96 & 35,15 \\
\hline 26 & indeks panen $(\%)$ & 22,65 & 41,00 & 66,58 & 31,93 & 39,28 \\
\hline
\end{tabular}


pada variabel produksi, maka didapatkan 12 klon paling unggul, yaitu Daniel Cabang 40, BL 8-1, SL 36, Mulyo 190516, MU 35, UJ 5 CMM 96-1-102, MU 111, CMM 97-6-1, SL 121, UJ 3, dan Thailand Tinggi.

\section{KESIMPULAN}

Didapatkan keragaman pada variabel kualitatif dan kuantitatif, serta didapatkan beberapa klon dengan variabel produksi lebih tinggi dibandingkan UJ 5. Klon dengan daya hasil tertinggi yaitu Daniel Cabang 40 dengan 49,59 t/ha, BL 8-1 dengan 48,83 t/ha, SL 36 dengan 44,25 t/ha, Mulyo 190516 dengan 39,93 t/ ha, MU 35 dengan 31,90 t/ha, serta UJ 5 sebagai pembanding pada urutan 18 dengan hasil 11,37 t/ ha.Terdapat 17 klon yang memiliki daya hasil lebih tinggi dari klon pembanding UJ 5 sebagai klon unggul nasional.

Klon dengan daya hasil tertinggi yaitu Daniel Cabang 40 dengan 49,59 t/ha, BL 8-1 dengan 48,83 t/ha, SL 36 dengan 44,25 t/ha, Mulyo 190516 dengan 39,93 t/ha, MU 35 dengan 31,90 t/ha, serta UJ 5 sebagai pembanding pada urutan 18 dengan hasil 11,37 t/ha.

\section{UCAPAN TERIMA KASIH}

TerimakasihkepadaProf. Dr. Ir. Setyo Dwi Utomo, M.Sc. selaku pembimbing utama, Ir. NiarNurmauli, M. S. selaku pembimbing kedua, Ir. Sunyoto, M.Agr. selaku penguji, serta semua pihak yang telah membantu terselenggaranya hingga selesainya penelitian dan tugas akhir ini.

\section{DAFTAR PUSTAKA}

Adrianus. 2012. Pertumbuhan dan Hasil Tiga Varietas Ubi Jalar (Ipomoea batatas L.). Jurnal Agricola $2(1): 1-21$.

Balitkabi (Badan penelitian tanaman aneka kacang dan umbi). 2015. Cara Meningkatkan Kandungan Pati Ubi Kayu. http://balitkabi.litbang.go.id di akses pada 16 Juli 2019

BPS. 2015. Produksi Ubi Kayu Menurut Provinsi (ton) 1993-2015. www.bps.go.id. Diakses pada 11 juni 2017

Borlaug, N.E. 1981. Increasing and stabilizing food production. In Frey, K.J. (Ed.). Plant Breeding II. Iowa State University Press. Iowa, USA. p. 467-492.

Ceballos, H., J.C Perez, N. F. Calle, G. Jaramillo, J.I. Lenis, N. Morante, and J.

Lopez. 2002. ANew Evaluation Scheme for Cassava Breeding at CIAT. Dalam Proceeding of The Sevent Regional Workshop Held in Bangkok Howeler, R.H. ed. : CIAT : pp. 125-135

Dewi, E. S. 2016. Buku Ajar Mata Kuliah Pemuliaan Tanaman. Universitas Malikussaleh. Aceh

Fukuda, W. M. G., C. L. Guevara, R. Kawuki, and M. E. Ferguson. 2010.Selected

Morphological and Agronomic Descriptors for The Characterization of Cassava. International Institute of Tropical Agriculture(IITA), Ibadan, Nigeria. Nigeria. 
Kawano, K. 2003. Thirty Years of Cassava breeding for Productivity-Biological and Social Factors for Succes. Crop Sci. 43: 1325-1335

Nugraha. H. D., Suryanto. A., dan Nugroho. A. 2015. Kajian potensi produktivitas ubikayu(Manihot esculenta Crant.) di kabupaten Pati Jurnal Produksi Tanaman 3 (8) : 673 - 682.

Sundari, T., K. Noerwijati, dan I.M. J. Mejaya. 2010. Hubungan antara Komponen Hasil dan Hasil Umbi Klon Harapan Ubi Kayu. Balai Penelitian
Tanaman Kacang-kacangan dan Umbiumbian. Malang. 29(1):29-35.73

Tumewu. P., Paruntu. C. P., dan Sondakh. T. D. 2015. Hasil Ubi Kayu (Manihot esculenta Crant.) Terhadap Perbedaan Jenis Pupuk. Jurnal LPPM Bidang Sains dan Teknologi 2 (2) : 16-27

Utomo, S.D. 2012. Pemuliaan Tanaman menggunakan Rekayasa Genetik. Penerbit Lembaga Penelitian Universitas Lampung. Lampung. 170 Hlm. 